\title{
The Creation and Soul of Animation
}

\author{
Zhang Jin \\ (School of Art, East China University of Technology, nanchang, Jiangxi Province, China) \\ 298288207@qq.com
}

\begin{abstract}
Keywords: Visual Music; Art Language; Art Carrier; Art Content
\end{abstract}
\begin{abstract}
With the rapid advancement of modern electronic media technology, animation is booming as a new thing. As a fresh art category, it integrates electronic technology with various forms of art and pushes contemporary art into a new historical stage. However, because of the unique nature of animation, people now have doubts about animation and begin to equate the development of animation with the development of technology. This paper refutes this point. The core argument of the paper is that technology is not everything in animation and animation is an art. The paper elaborates the point that animation is an art from two parts, one is two standpoints of art itself and the source of art language; the other is the application of electronic technology in synaesthetia art and the source of art language, which will be helpful in the new and correct understanding of animation and its nature and features.
\end{abstract}

\section{Introduction}

In 1926, Wilfred of Philadelphia invented Clavilux and used this machine to perform the famous symphony of Zeus. The author equated color with music and developed the synaesthetia theory proposed by the founder of abstract painting Kandinsky to another level. The performance in Philadelphia brought two innovations in the field of art. First, its emergence represented the first complete integration of electronic technology and art in human history; second, it also meant the production of a new form of art. In this performance, the art forms, such as painting, music and lighting, were integrated on the same platform. The advantages of various arts were organically combined and developed to another level, which is "Visual Music" which we all know ${ }^{[1]}$.

The emergence of animation was relatively late. Animation is also a product of electronics, however, it contains a large number of electronic technologies, people begin to forget the connection between three-dimensional animation and art and consider it as a product of the development of pure electronic technology. Actually, we can analyze the basic nature and content of animation: painting, music, lighting, movements and so on. Both animation and "visual music" which is mentioned in the previous paragraph are art forms. The electronic technology in animation is actually a means of the art form of $3 \mathrm{D}$ animation, or a more thorough explanation is an exhibition form of an art form, just like the brush and paper used by a painter or the instrument and stage used by a musician ${ }^{[2]}$. Electronic technology is the carrier of animation. Reproducing various kinds of arts is the content of animation.

Content and carrier are two different concepts, belonging to different systems, one is appearance and the other one is the essence of things. With the development of modern electronic technology, under the dazzling brilliance of electronic technology, people gradually forget the essence of 3D animation, blur its own characteristics and essence and forget that 3D animation is another emerging art form. People often make mistakes in recognizing things and often confuse the nature and appearance, so there will be an understanding of animation.

We can once again discuss what art is. This issue has been discussed by humans for a long time. (The art discussed here do not refer only to art and music. The scope of art is very large, not all of which are listed here.) People have various answers to this question. The essence of art is that artists use the artistic language they understand and summarize to speak and discuss certain things or issues on a presentation platform. Just like Chinese and English, they are all elaborating the same things. These languages can be either specific or abstract, can be received by eyes or ears, and can also be felt with other sensory organs. Then painting has a painting language, music has a music 
language and movie has a film language. Therefore, an animation that is also art has its own unique artistic language. Then there is a new question: What are the languages that animators create and use? What animators actually do is to integrate all kinds of artistic languages, make these which seemingly disparate be related and assimilate, and use the technical advantages of animation to process and recreate the language ${ }^{[2]}$. The creation process of animation artists is: analysis, integration, reanalysis and integration and finally create an artistic language that belongs to animation. In fact, this process is the same as the creation way of Cubism that we are familiar with: analysis, breaking, analysis and finally recombination. From the development of Prague, Cubism derived collage art. Although it is not very precise, in terms of its artistic form and creative process, animation may also be the extension and development of collage art.

We all know that shadow puppetry is a bright pearl in Chinese folk art. Its vivid image and obvious artistic features have affected many Chinese people. But in today's era, this art form is declining and gradually withdrawing from people's daily lives. What can we see from its decline? First of all, we can make an analysis of its own characteristics. Shadow puppetry is actually an animation when there was no modern electronic technology ${ }^{[3]}$. We can recall that the Chinese animation in the early days of the founding of the PRC was actually a re-enactment of shadow puppetry on television or movie screen. All the shape, the light and the overall effect are basically the same. It can be said that the animation at that time was the result of the combination of shadow puppetry and electronic technology. It was the continued development of shadow puppetry on the electronic platform. As an upgrade of two-dimensional animation, how can we say that three-dimensional animation is not an art? This will not only make all the existing shadow puppetry relive the light of day, but also add various modern elements to shadow puppetry to make it truly meet the needs of the times. At the same time, the development of animation can instill fresh blood into traditional Chinese art and modern science and technology and promote its development ${ }^{[4]}$.

Second, we can examine this issue from the perspective of the development of modern society. The major trends in the development of modern society are: the pace acceleration and the rapid integration. All technology and information and human beings have gathered in this fast paced rhythm. Both things and people are constantly changing. The development of animation conforms to the changes in historical development and the trend of social development. Animation is an emerging art that adapts to the direction of historical development. For art, our assessment of art cannot always stand still and we cannot use old ideas or artistic concept to perceive art. But people need time to understand these new perceptions. It took a lot of time for people to understand and accept Galileo's Sun-centered theory. It is always difficult for people to recognize modern things when they comment them from the present perspective. Perhaps at the time of electronic music, people did not treat it as an art. We can make a bold assumption. Perhaps a few years later when science and technology develop to a height that people cannot even imagine now, people might think that animation is actually a very ancient form of art when they talking about the current three-dimensional animation, just as the ancient frescoes in French caves now. People will not lose sight of the direction of judgement because of the beauty or the complexity of electronic technology that is not available in the past. As cognition begins to change, traditional aesthetic norms are no longer suitable for modern people. With the help of new media, the new aesthetic logic has quietly infiltrated the ideology of modern people. The standard of beauty has never been an eternal thing. The unique aesthetics of each generation is naturally formed by the characteristics of contemporary life.

In addition to the extraordinary special effects and eye-catching light dancing, details are the most impressive part which are also the magical charms of animation art. Whether it is a movie production or a one-minute personal short film, it is necessary to animate something extraordinary in order to be unique. This requires animators to master a variety of art forms, and even to change between different art forms. Because there are too many contents covered by animation and there are various possible roles. Character of an animation may be human or animals. Each character is vivid and has its own character. It is very difficult for animators to make all kinds of images be vivid $^{[5]}$. 
More and more animators lose their direction, only pursuing truth and mastery of software technology. It is undeniable that the premise of animation production is to master the software, but it does not mean that technology is everything in animation. In fact, nowadays, for some mainstream software, 3d max, Maya and XSI, only a few modules and some simple commands need to be mastered in order to create a good work. Animators are not technical craftsmen. They are people who need creative thinking from time to time. He is ready to become an animated character he portrays. The most important thing is not how perfect the character's step line is or how realistic the character's texture drawing is, but how to make animation character alive. The production of characters in famous foreign films such as Shrek and Shark Tale are not difficult to achieve. They all appear as abstract characters and their technical contents are relatively less. However, foreign three-dimensional animation artists have vividly displayed the life of characters, making audience feel that the characters have lives, emotions, even joys and sorrows as real living creatures, which is based on animators' observations ${ }^{[6]}$.

We can recall the famous American two-dimensional animation film The Lion King (1996). Although it has passed many years, its grand scenes and vivid characters are still vivid. In the film, we should focus on the performance of its scene. Lions are animals living in savannah and are mainly distributed in Central Asia, West Asia and Africa. The savannah of Africa is the most typical. There are not a lot of bushes on savannah, but only sparse tall crowned trees and patches of thorn bushes. The scenes in The Lion King are precisely in line with this ecological environment. In addition, we can also find that the story is also originality. In savannah, dogs and lions are at the top of the food chain. In real nature, these two animals are hostile. That the lion kills the dog and the dog sieges the lion and takes food is commonly seen. This natural relationship has been well illustrated in The Lion King. In fact, there are many other places which are worthy of our understanding and scrutiny. We will not elaborate here. The bits and pieces in the film are unique. Everything here is inseparable from the daily accumulation and careful observation of animators.

From capture to post-production, the traditional animation is very different from today's. Although traditional animation continues to use new technology in order to create better audio-visual effects, under certain technical conditions, traditional animation has the same concerns to the artistic elements of animation itself and creates animation as a whole art form. In comparison, animations made in the traditional way have more attention to the art than to the technology. As a comprehensive art, the traditional animation features are very obvious. Disney once said: "The primary responsibility of animation is to animate life and actions, that is, to present things on the screen through audience's imagination, rather than photograph or depict life or actions. It is to animate things encountered in real life or present the wonderful things we think about today. Many people often have incorrect ideas when studying real actions and consider the purpose to be only to draw these actions as they are, which should be fundamentally scraped." "Authentic animations are real or possible things, even things that are about to happen with fantasy and exaggeration." The so-called "cartoonization" or "fantasy and exaggeration" are mainly reflected as adding the factors of comedy to the features of characters. The cartoonized contents should also include recreating the image, exaggerating and deforming the character. Therefore, properly use the artistic characteristics of painting, clay sculpture, paper cutting, etc. fully show and give play to the characteristics of each art. For example, ink animations created by Chinese animators have fully utilized the fun of Chinese ink painting. People appreciate the artistic charm of Chinese painting while enjoying the $\operatorname{animation}^{[7]}$.

Freud said that art, as "an imaginative creation, is just like a dream in day. It is a continuation and replacement of childhood games." The animation itself is to directly display the contents which are difficult to be displayed by ordinary means such as fairy tales, myths, science fictions, etc. Animation is a carrier for people to produce interest and fantasy. As Disney said: "I'm not mainly making films for kids. It is for the innocence of all of us (whether he is 6 or 60 years old). It's called innocence. The worst thing is not that we do not have innocence, but we may bury them. In my work, I try hard to realize and express this innocence, let it show the fun and joy of life, show the health of laughter, show humanity, though sometimes it is ridiculous, but I still have to work hard." 
Animation is to meet people's imagination space through illusion. Therefore, it is not only loved by children, but also attracts many adults ${ }^{[8]}$. Freud also said: "Artists' creations - works of art - just like dreams, are the satisfaction of the unconscious desires in imagination; art works have harmonic natures like dreams, because they also have to avoid any open conflicts with repress power. But the works of art are not the products of self-centered narcissism in dreams, because the works of art are intended to arouse the resonance of human, evoke and satisfy the same unconscious desire impulses of human." There is still a certain distance between imagination and reality. Therefore, works of art must also be distinguished from the realities of real life. However, in recent years, animation films that created box office miracles or won various movie awards have shown such a tendency that to show the real world as if it were a virtual reality by the ability of realism vigorously and high-tech means. The three-dimensional animation is undoubtedly the most effective way to produce realistic effects.

\section{Summary}

Animation is a comprehensive art with the dual attributes of art and technology. Computer animation is a product of the combination of computer graphics and art. It provides people with a new world in which they fully demonstrate their personal imagination and artistic talents. People still appreciate animation as an overall art form. Although, the application of computer technology can also achieve the artistic effects that traditional hand-painting can achieve and even better, when animation only relies on technology and discards other, the overall artistic effects of the animation will be weakened as the virtual reality. Therefore, it is difficult to achieve a good animation in any aspect. In the age of high technology, proper use of technical means in animation to create better artistic effects is worth advocating. However, if technology is taken as the only objective to be displayed in animation, the artistic life of animation will become weaker and weaker. Although people will be shocked by the visual effects displayed by new technologies for a short period of time, when it becomes commonplace, people are still willing to appreciate the artistic characteristics of the animation itself. Therefore, the animation community should keep a clear head in the face of high-tech applications. It can neither be conservative or evade the new technologies or only rely on the tradition; nor blindly seek new ideas, pursue new technologies and the new achievements in displaying technology and reduce the pursuit of animation artistic effects. Only to better express the artistic effects of animation by new technologies will create successful animation works.

\section{References}

[1] Kerry Brougher ,Jeremy Strick Visual Music Synaesthesia in Art and Music Since 1900 Thames \& Hudson London p15-p45

[2] Wassily Kandinsky Concerning the Spiritual in art 7 Wittenborn Art Books, Inc,New York p48

[3] Irving FangA History of Mass Communication, Boston: Focal Press, 1997.p41

[4] Nicholas Negropont Being Digital,New York: Vintage Books, 1996. p15

[5] Wen Yuan, Liu Kai, etc. Three-Dimensional Art. Electronic Industry Press. 2003 Edition.

[6] Gu Juyi Edit. Digital Art Forum. Zhejiang People's Fine Arts Publishing House, January 2002, 1st Edition.

[7] (U.S.) Rudolph Ainheim. Art and Visual Perception. Translated by Teng Shouyao and Zhu Jiangyuan. Beijing: China Social Sciences Press. 1984.

[8] Han Xiao Film and television Animation Scene Design Chief Sun Lijun Author: astronavigation publishing house in 2003 June 1st publish p16 